\title{
Precariedad laboral y trayectorias flexibles en México. Un estudio comparativo de tres ocupaciones
}

\author{
Alfredo Hualde Alfaro \\ El Colegio de la Frontera Norte \\ ahualde@colef.mx \\ Rocío Guadarrama Olivera \\ Universidad Autónoma Metropolitana. Unidad Cuajimalpa \\ rocio.guadarrama.o@gmail.com \\ Silvia López Estrada \\ El Colegio de la Frontera Norte \\ slopez@colef.mx
}

Recibido: 08-01-2015

Aceptado: 04-11-2015

\section{Resumen}

En el contexto actual de globalización, reestructuración de los procesos productivos y flexibilización del trabajo, las investigaciones académicas coinciden en señalar que el trabajo contemporáneo se caracteriza por una condición de precariedad muy extendida. En este artículo se presentan los principales hallazgos de un estudio sobre la precariedad en México que parte de considerar la heterogeneidad del fenómeno y su fuerte carga subjetiva. Para dar cuenta de dicha diversidad y de su evolución, se comparó la situación laboral de individuos de tres ocupaciones contrastantes en diferentes regiones del país: trabajadores de la industria de la confección, de centros de atención de llamadas y músicos profesionales. La investigación empírica estuvo sostenida por una metodología mixta que permitió la reconstrucción de los itinerarios laborales de los trabajadores a partir de la información obtenida mediante entrevistas semiestructuradas. Se concluye que la inestabilidad y la incertidumbre son predominantes excepto en segmentos de trabajadores de la industria de la confección empleados en las grandes multinacionales, en los trabajadores que hacen carrera en los centros de atención de llamadas y en los músicos con plaza en las orquestas más estables. En estas condiciones, el significado del trabajo es múltiple y exige de los individuos adaptaciones permanentes a lo largo de su vida laboral.

Palabras clave: precariedad; heterogeneidad; industria de la confección; centros de atención de llamadas; músicos profesionales 
Abstract. Labor precariousness and flexible trajectories in Mexico: A comparative study of three occupations

In the context of globalization, productive restructuring and labor flexibility processes, scholars agree that contemporary work features a state of extended precariousness. This article presents the main findings of research done on precariousness in Mexico, taking into account the heterogeneity as well as the subjectivity of this phenomenon. In order to show these processes, the labor situation of individuals from three contrasting occupations in different regions of the country was compared: garment industry workers, call center workers and professional musicians. The empirical inquiry was based on a mixed methodology, with information collected from semi-structured interviews used for the reconstruction of workers' labor itineraries. Overall, the study shows that instability and uncertainty are predominant features among workers of the three occupations, and only some garment workers in transnational companies, career workers in call centers and tenured musicians in large orchestras escape from precariousness. Individuals respond to this situation through permanent adaptations along their labor trajectories, and the meanings of work are multiple.

Keywords: precariousness; heterogeneity; garment industry; call center; professional musicians

\begin{aligned} & \multicolumn{2}{c}{ Sumario } \\ & Introducción Tipos de trayectorias por ocupación \\ & $\begin{array}{r}\text { Del enfoque estructural de la precariedad } \\ \text { al análisis de las trayectorias precarias }\end{array}$ Elementos secuenciales de la precariedad \\ & Abordaje metodológico Trayectorias, subjetividad y agencia \\ & e instrumentos utilizados Comentarios finales \\ & Contextos económicos, espaciales y Referencias bibliográficas \\ & organizativos en las tres ocupaciones \end{aligned}

\section{Introducción}

En los años ochenta, a escala internacional, comienza una nueva etapa en la desregulación de los mercados laborales que impulsa una tendencia a la precarización del trabajo (Castel, 1997; Paugam, 2000; Lautier, 1999; Pacheco, 2004; García y Oliveira, 2001; García, 2006 y 2011; Salas, 2007). En México, la ola privatizadora y de desregulación tiene sus propias expresiones a partir de la crisis de la deuda y los ajustes diseñados por el Fondo Monetario Internacional. En los mercados de trabajo la privatización de las empresas públicas, la contención de la inflación por la vía salarial y la erosión de los contratos colectivos son algunos de los rasgos que caracterizan a dicha etapa. En términos generales, en los últimos treinta años, estas tendencias se han agudizado y profundizado (Bensusán y Middlebrook, 2013; Pacheco et al., 2011; Reygadas, 2011) ${ }^{1}$.

1. En este sentido, las reformas a la Ley Federal de Trabajo, aprobadas a finales del año 2012, constituyen la consagración por la vía legal de lo que ya era real en los mercados laborales. 
Aunque la situación de México no es totalmente coincidente con lo sucedido en otros países de América Latina, en los que, entre 2002 y 2013, se redujeron las tasas de desempleo y de informalidad, así como la desigualdad salarial ${ }^{2}$, el panorama actual y los pronósticos de corto y mediano plazo para el conjunto de la región son poco halagüeños. De acuerdo con los datos analizados por la OIT (2014a: 8), desde mediados de 2013, la desaceleración económica ha producido un conjunto de fenómenos en el mercado de trabajo que confirman la «normalización» de la precariedad laboral en dicha región del mundo 3 .

Acerca de las diversas manifestaciones de esta tendencia precarizadora, existe ya una amplia bibliografía internacional que, desde distintos ángulos analíticos, condensados en conceptos como informalidad, exclusión, vulnerabilidad y precariedad, explica y describe las condiciones estructurales en que se desenvuelve el trabajo en diferentes sectores y regiones del mundo (Bayón, 2006; Castel, 2009; Clert, 1997; ESOPE, 2005). Sin embargo, es menos lo que se ha escrito en México sobre el carácter procesual y subjetivo de este fenómeno ${ }^{4}$. Por esta razón, en la presente investigación privilegiamos un enfoque de la precariedad que analiza de manera combinada sus condiciones objetivas y subjetivas, y pone al descubierto las diferencias sutiles entre ocupaciones - manuales y no manuales, de servicios e industriales, de sectores tradicionales y las más recientes vinculadas a las nuevas tecnologías y a la cultura—, cruzadas todas ellas por las diferencias no menos importantes entre hombres y mujeres. Una exposición ampliada de esta perspectiva se presenta en Guadarrama et al. (2014).

La persistencia de la precariedad como tendencia indiscutible del mundo contemporáneo remite, a su vez, a una línea de reflexión que cuestiona la vigencia de las fronteras establecidas entre trabajo y empleo. El primero es entendido como una actividad puramente mercantil y el segundo, como un contrato entre empleadores y empleados que no solo matiza las características mercantiles del intercambio por estar sujeto a determinadas garantías y mínimos establecidos, sino que hace del trabajador un ciudadano sujeto de derechos (Castel, 1997) ${ }^{5}$. En la actualidad, en los mercados laborales se reconocen formas más heterogéneas y dinámicas que cuestionan las dicotomías más habituales y agregan complejidad al mundo del trabajo y a la estructura social. Nuestras reflexiones se orientan hacia esta dirección.

2. Se citan como causas de ese cambio de tendencia temporal: el crecimiento económico, especialmente en el Cono Sur y en los países andinos, y ciertas políticas y reformas institucionales (Weller, 2014).

3. Entre ellos, destacan la disminución en la tasa de participación, sobre todo de mujeres y jóvenes, y, como resultado de esto último, un estancamiento sui géneris del desempleo. En conjunto, todos estos factores producen desaliento y frustración entre los trabajadores, que experimentan un empeoramiento en la calidad del empleo y una baja en el ritmo de crecimiento de los salarios.

4. Para el caso de España, se pueden consultar Castillo y López Calle (2007), Santamaría (2012) y López-Andreu y Verd (2013).

5. En América Latina, la extensión del empleo formal a mediados del siglo xx fue una característica fundamental de un tipo de modernización que actualmente ha sido rebasada por la globalización y la flexibilización del trabajo (Pérez Sainz, 2014). 
Para abordar estas nuevas dimensiones del mercado laboral, nos ceñimos a una estrategia que propone, como niveles de análisis principales, la ocupación y la región, articuladas en las trayectorias laborales de trabajadores de tres ocupaciones contrastantes en el mercado laboral mexicano ${ }^{6}$. Por un lado, tomamos el caso de la industria del vestido, una industria tradicional que ilustra muy bien la situación de las actividades económicas globalizadas, donde, al menos hasta el comienzo del siglo XxI, se empleaba mano de obra mayoritariamente femenina ${ }^{7}$ (Barrios y Hernández, 2004; Camacho, 2001; Miker, 2001; Bair, y Gereffi, 2003; Castilla y Torres, 2009). Por otro lado, se estudia a los operarios de centros de atención de llamadas, sector ligado a las nuevas tecnologías de la información, que ha sido caracterizado como neotaylorismo informático o digitofactura, para subrayar el carácter rutinario y estandarizado de la actividad laboral que atrae de manera preferente a jóvenes con mediana y alta escolaridad (Micheli, 2006; Lanciano et al., 2009; Holman et al., 2007). La tercera ocupación seleccionada es la de los músicos profesionales. Particularmente, nos referimos a los músicos intérpretes y a los dedicados a la enseñanza de la música y la capacitación artística. Su estudio permite observar uno de los rasgos característicos de la precariedad laboral en el mundo contemporáneo (Menger, 2009). Nos referimos a la multiactividad, a la que Boudy (2009: 42) llama una práctica «antigua y persistente».

Cada una de estas ocupaciones se investigó en distintas regiones del país (ver mapa 1) teniendo en cuenta las diferencias por tipo de empresa y, en el caso de los músicos, el tamaño y el prestigio de las orquestas y los diferentes establecimientos escolares: la industria de la confección, en la región Lagunera (centro-norte), Tijuana (frontera noroeste) y Valle de Tehuacán (centro); los trabajadores de centros de atención de llamadas, en Tijuana, Monterrey (norte) y en el Distrito Federal, y, finalmente, el trabajo acerca de los músicos se desarrolló en el Distrito Federal y en Tijuana.

En el siguiente acápite, discutimos de manera más detallada las potencialidades y los rasgos fundamentales de este enfoque basado en el análisis de trayectorias, en un contexto dominado por ciertos rasgos estructurales persistentes que analizamos brevemente. Acto seguido, se presentan los instrumentos heurísticos y los resultados de esta investigación, que pone el acento en el aspecto subjetivo y estratégico de las trayectorias, examinando tanto la capacidad de agencia de los trabajadores como las restricciones a la misma.

6. Las empresas u organizaciones donde se emplean estos trabajadores no son un objeto de análisis per se, aunque se toman como un referente importante en la parte contextual y en los instrumentos de análisis, tanto en el cuestionario como en el guión de entrevista. En consecuencia, los testimonios de los trabajadores permiten entender algunas de sus dinámicas y lógicas organizativas (ver apartado metodológico).

7. Algunos autores hacen notar la masculinización progresiva de la mano de obra desde finales del siglo xx (De la O, 2006). 


\section{Del enfoque estructural de la precariedad al análisis de las trayectorias precarias}

A pesar de los cambios causados por la flexibilidad y las políticas desreguladoras, en el mercado de trabajo mexicano persisten una serie de rasgos estructurales que, en ciertos aspectos, son comunes a otros países de América Latina. Uno de ellos es la fuerte presencia del sector informal en el que está ocupada casi el 60\% de la fuerza de trabajo (OITb, 2014; INEGI, 2014). Para analizar estas persistencias, y también los cambios observados, preferimos tomar el concepto de heterogeneidad (García y Oliveira, 2001; Pacheco, 2004; Guadarrama et al., 2014), que, desde nuestro punto de vista, amplía la idea del dualismo formal/informal y apunta hacia una diferenciación más compleja en segmentos múltiples del mercado de trabajo. De esta manera, hacemos ver que aún los segmentos más formales están salpicados por rasgos y usos de la economía informal.

Derivado de lo anterior, sostenemos que las políticas de flexibilidad ${ }^{8}$ y la insuficiente creación de empleos formales favorecen esta heterogeneidad desde la década de 1980, aunque ya durante el llamado periodo fordista convivían formas de regulación protectoras o garantistas en las grandes industrias nacionalizadas (siderurgia, ferrocarriles), así como en una parte importante de las administraciones públicas, con amplios sectores desregulados en el comercio y la pequeña industria (Villarreal, 1988; Zapata, 1993; Marshall, 1996). Al respecto, Reygadas (2011: 27) afirma que la mayoría de la población activa nunca ha tenido empleos estables y protegidos en México. Por ello, no es sorprendente que, hoy en día, después de tres décadas de políticas de flexibilidad y desregulación únicamente un número relativamente reducido de trabajadores perciba las prestaciones sociales de ley y sean todavía más raras aquellas como seguros médicos privados, bonos de productividad y primas de antigüedad otorgadas por ciertas empresas privadas y unas pocas empresas e instituciones públicas. Se calcula que, en 2012, del total de trabajadores ocupados sólo un tercio estaban afiliados al Seguro Social; entre los asalariados el porcentaje de afiliados asegurados ascendía a la mitad (Pacheco, 2014).

Los análisis de tipo estructural, que pusieron en evidencia los límites del empleo seguro, no contemplaron, sin embargo, sus efectos duraderos ni tampoco sus puntos de inflexión en la vida de las personas. Para profundizar en esta dimensión del fenómeno de la precarización del trabajo, que nos permite conocer sus contradicciones más sutiles, en el presente artículo adoptamos una perspectiva longitudinal que intenta situarse también en el terreno de los acontecimientos y de la contingencia. Desde este ángulo, se destacan las capacidades desiguales de agencia de los sujetos y sus posibilidades para utilizar

8. Las políticas de flexibilidad tienen como directriz el control del tiempo de trabajo en el proceso productivo, por lo que se combinan jornadas completas y parciales, se contabiliza la dedicación laboral desde horas hasta años y varían los ritmos y los turnos, así como las horas extra. Además, existen temporalidades estacionarias y la intensidad horaria varía según las exigencias del mercado (Lozares y Miguélez, 2007; Torns, 2005). 
recursos de distinta índole a lo largo de su trayectoria, que, eventualmente, les permiten orientar su trabajo y su vida hacia objetivos que consideran deseables. Estas capacidades desiguales, así como los diferentes contextos en los que transcurren sus trayectorias, producen itinerarios diversos con temporalidades disímiles y "desenlaces» a veces inesperados que indican ciertas tendencias a las que llamamos configuraciones. Lo que se pone en juego en esta relación compleja entre estructura y agencia es la configuración de las trayectorias (o las varias configuraciones que se construyen a lo largo de las trayectorias), en la que intervienen actores, contextos y también circunstancias a escalas múltiples. Esto hace suponer que no hay determinismos en la acción social, pero tampoco una capacidad de acción sin límites y que, además, el margen de maniobra de los individuos es variable en el tiempo.

De manera particular, se propone que el tipo de ocupación al que los individuos se adscriben, ya sea por elección o de manera forzada, prefigura una serie de posibilidades, un conjunto de trayectorias y figuras de referencia que contribuyen a orientar las estrategias de los individuos y de los grupos profesionales, porque forman parte de los saberes de la ocupación o de la profesión (Bidart y Konig, 2014: 2). En este sentido, suponemos que la trayectoria de referencia se construye en el texto a lo largo del tiempo como una acumulación de saberes, en contextos en los que la flexibilidad produce puntos de inflexión constantes en las trayectorias. Es así que el camino imaginado por el individuo para llegar a una figura de referencia, que encarna el objetivo a lograr, puede sufrir cambios que lo lleven a separarse de su trayectoria ideal y a imaginar objetivos más versátiles y realizables.

Lo que importa, entonces, es reconocer que las trayectorias laborales no son únicamente una acumulación de empleos en el tiempo, sino caminos imaginados, cambiantes, buscados y evaluados por los propios individuos en un momento dado, dentro de ciertos mercados, contextos ocupacionales y dispositivos institucionales que limitan su acción.

Por eso nuestro interés por estudiar las condiciones variables a las que se enfrentan los individuos en ocupaciones contrastantes. En un extremo, estudiamos a los músicos profesionales con firmes acervos de conocimientos y destrezas, algunos con carreras largas y estatus laborales más altos; otros que dan más peso a la experiencia profesional que al estudio, y, por último, otros más que basan su carrera en la experimentación constante y en un conjunto de experiencias diversificadas. En contraste, consideramos ocupaciones «transitorias», como las de los centros de atención de llamadas, que se han convertido, con el tiempo y por la falta de oportunidades, en reductos de empleo para una buena parte de los jóvenes que estudian y trabajan, pero también es una de las pocas opciones de que dispone un sector de adultos con trayectorias profesionales truncadas. Finalmente, en la confección de ropa, ocupación tradicionalmente femenina pero en la que los hombres tienen cada vez más peso, la acumulación de conocimientos está basada más en la experiencia, que - a pesar de los cambios impuestos por los mercados flexibles y la internacionalizaciónpermite en algunos casos construir identidades que están sujetas a la obtención de cierta seguridad en el empleo y la búsqueda de mejoramiento económico. 
Para establecer puntos de comparación entre universos tan disímiles, partimos de reconocer un criterio objetivo: la continuidad o discontinuidad de los individuos en la ocupación y en el mercado de trabajo. El supuesto tras este criterio es que la continuidad en la ocupación implica una acumulación de conocimientos y de relaciones, sea en las empresas, en otros centros de trabajo públicos, privados o sociales, o en el trabajo por cuenta propia, que facilitarían una trayectoria ascendente y el logro de mejores condiciones laborales. Este supuesto, como veremos, se cumple solo en ciertos casos.

En el análisis de las trayectorias por ocupación, se toman en cuenta, además, otros elementos tales como los ingredientes del contexto, las secuencias de los eventos, las fuerzas impulsoras y las rupturas o bifurcaciones que se muestran a lo largo del trayecto biográfico-laboral (Bidart et al., 2013). Enfatizamos también acontecimientos macro o meso, como crisis económicas o cierres de empresas, la temporalidad (o temporalidades) de dichos contextos y su impacto en la biografía de los individuos (posibilidades de estudio, cambios en la vida familiar, migraciones, etc.), que conforman los marcos relacionales y temporales de las trayectorias, pues tanto la visión ligada al proceso como la concepción de la acción se basan en una perspectiva temporal y cambiante de las estructuras (Emirbayer y Mische, 1998). Estos son los marcos de la acción que tuvimos en cuenta para analizar las trayectorias de los individuos de las tres ocupaciones consideradas en esta investigación.

A su vez, buscamos conocer su propia interpretación y valoración de estos contextos, y la evaluación acerca de sus posibilidades de acción de acuerdo con sus experiencias del pasado (agencia iterativa), sus expectativas de futuro (agencia proyectiva) y su interpretación del presente (evaluación práctica) (Emirbayer y Mische, 1998: 971).

\section{Abordaje metodológico e instrumentos utilizados}

De acuerdo con las consideraciones anteriores, en esta investigación, construimos una propuesta que contempla tres ejes de análisis fundamentales: $a$ ) el eje estructural de la heterogeneidad, que considera las diferencias de la precariedad laboral por ocupación, región y sexo; $b$ ) el eje diacrónico o temporal, que muestra el carácter histórico-biográfico de este fenómeno, plasmado sobre todo en el análisis de trayectorias, y $c$ ) el eje de la subjetividad, que subraya las ambigüedades y las contradicciones de la precariedad desde el punto de vista del sujeto. A continuación, explicamos cada uno de dichos ejes, aunque en el presente artículo desarrollamos únicamente el segundo y el tercero.

El primer eje se ciñe al concepto limitado y descriptivo de la precariedad laboral, referido a situaciones de empleo y trabajo, según diferencias sectoriales, regionales y por sexo, que muestran la heterogeneidad del fenómeno y permiten establecer la comparación a partir de ciertos indicadores.

El segundo eje analítico de esta propuesta, referido al carácter diacrónico de la precariedad, se desarrolla a través de un estudio de trayectorias en el que se entrelazan los indicadores objetivos de la heterogeneidad con los aspectos 
subjetivos del fenómeno. Esta estrategia muestra también el carácter no determinista de la precariedad, que puede revertirse o profundizarse en determinados contextos familiares, formativos, laborales, regionales y trasnacionales de las trayectorias de vida de las personas.

Por último, el tercer eje de análisis aquí presentado intenta recuperar los aspectos valorativos del fenómeno y mostrar que la heterogeneidad se refiere, en el fondo, al distinto significado que los individuos otorgan a la precariedad y que se traduce en valoraciones sobre el deterioro de su nivel de vida o de sus condiciones de salud; en otras ocasiones, remite a experiencias de fracaso profesional experimentadas al no encontrar empleos que correspondan a sus años de formación y entrenamiento o al sentimiento de incertidumbre que experimentan quienes trabajan sin ninguna seguridad laboral ni social.

La estrategia de análisis arriba descrita está sustentada en una metodología mixta que se propone integrar los tres ejes de análisis y sus correspondientes procedimientos metodológicos y técnicos (Tashakkori y Teddlie, 1998; Newman y Benz, 1998). Estos autores consideran distintos estilos o formas de combinar los procedimientos cuantitativos y cualitativos de recolección y análisis de datos. En nuestro caso, seguimos una combinación secuencial predominante que considera dos etapas: la primera es exploratoria, de tipo cuantitativo (descriptiva), que pone las bases para la construcción de los datos; la segunda etapa pertenece a un diseño de tipo cualitativo (interpretativo).

En la primera etapa, se hacen patentes las dimensiones objetivas de la precariedad y se explora su naturaleza y las posibles relaciones en cada sector de ocupación, así como los puntos de comparación entre ellos. En la segunda etapa, se toman estas mismas dimensiones para analizar las experiencias de los propios individuos y sus maneras de evaluar la precariedad.

El ejercicio cuantitativo consistió en una encuesta con cuestionario realizada en el año 2010 a una muestra intencional de 255 individuos (89 trabajadores de la industria de confección de ropa, 86 trabajadores de centros de atención de llamadas y 80 músicos profesionales), seleccionados según distintas edades y distribución por sexo. De esta manera, se integraron en la encuesta trabajadores con características contrastantes respecto a su situación en el empleo y en el mercado de trabajo, con el propósito de tener la mayor diversidad posible de casos. Este procedimiento intencional también permite analizar la información en un contexto en el cual la edad, el sexo, la educación de los entrevistados y la educación de sus padres conforman un cuadro sociodemográfico útil por ocupación. Aunque la selección no es estadísticamente representativa ni permite inferir generalizaciones propias del análisis cuantitativo, guarda una coherencia interna con los enunciados teóricos sostenidos por otras investigaciones sobre la enorme variabilidad del fenómeno. También responde a los perfiles de las poblaciones estudiadas reportadas por los censos y las encuestas de población, así como por otros estudios de corte cuantitativo. En este sentido, nos permitió documentar la mayor diversidad posible de los atributos específicos de la precariedad laboral en cada una de las poblaciones estudiadas. Sobre esta base, se construyeron las tipologías de trayectorias que guiaron la selección de casos típicos para el 
estudio cualitativo en profundidad de las experiencias de la precariedad. Para ello, tomamos principalmente los datos sobre el número y la simultaneidad de eventos (empleos), así como su duración desigual en el tiempo. Al final, esta «transferencia» o cualificación de las descripciones cuantitativas iniciales muestra la congruencia o validez «interna» de los resultados obtenidos en la investigación.

La segunda etapa cualitativo-interpretativa de la investigación se basa en entrevistas semiestructuradas aplicadas entre 2010 y 2011 a individuos seleccionados a partir de las tipologías previamente construidas (entre 25 y 30 entrevistas por ocupación). Dicho instrumento tiene un papel fundamental en esta investigación, ya que permite establecer comparaciones entre ocupaciones y averiguar la manera como los individuos interpretan el sentido y las condiciones de su trabajo. Los principales ejes temáticos en la entrevista son, en principio, los identificados previamente en la encuesta. En este sentido, el procedimiento mixto supuso un acoplamiento en dos etapas, tanto de la selección de los individuos entrevistados como del diseño de los instrumentos utilizados (cuestionario y guía de entrevista). Este acoplamiento instrumental se continuó en la etapa de análisis de datos, principalmente en la elaboración de las tipologías de trayectorias laborales, construidas a partir de los datos sobre los empleos tomados del cuestionario (número de eventos y duración de los mismos; sectores de actividad; tipo y duración del contrato; ingresos, y entradas y salidas del mercado de trabajo), pero también de los testimonios de las entrevistas en profundidad relativos al significado de los empleos, a la valoración del trabajo y al sentido de la trayectoria.

Por último, este análisis mixto se contextualizó con cifras que ilustran las dimensiones del mercado de trabajo en cada una de las ocupaciones según la disponibilidad de fuentes públicas (el censo de población para los músicos) o privadas (Cámara Nacional de la Industria del Vestido para los trabajadores de la confección y las publicaciones de la Asociación Mexicana de Telemarketing para los centros de atención de llamadas).

A continuación, se muestran los resultados del trabajo basándonos en el marco analítico arriba señalado. Con este propósito, se describen sucesivamente: a) los aspectos contextuales pertinentes de cada ocupación; $b$ ) los tipos de trayectorias por ocupación, y $c$ ) los significados y las estrategias en el trabajo.

\section{Contextos económicos, espaciales y organizativos en las tres ocupaciones}

La historia de la industria de la confección es diferente en cada una de las ciudades y de las regiones seleccionadas (ver mapa 1). Así, en Tijuana, ciudad pionera en el establecimiento de las maquiladoras, situada en el extremo noroeste del país, la confección creció en una primera etapa y, posteriormente, decayó a partir de los años ochenta y noventa, porque algunas empresas se trasladaron hacia el centro-sur de México y hacia Centroamérica para bajar costos. En contraste, la Región Lagunera, en el norte-centro, con una larga tradición textil previa, y el Valle de Tehuacán, en el centro del país, forman parte de los territorios donde se asentó la segunda generación de maquiladoras. En estas 
Mapa 1. Regiones y ocupaciones seleccionadas para realizar el estudio de la precariedad

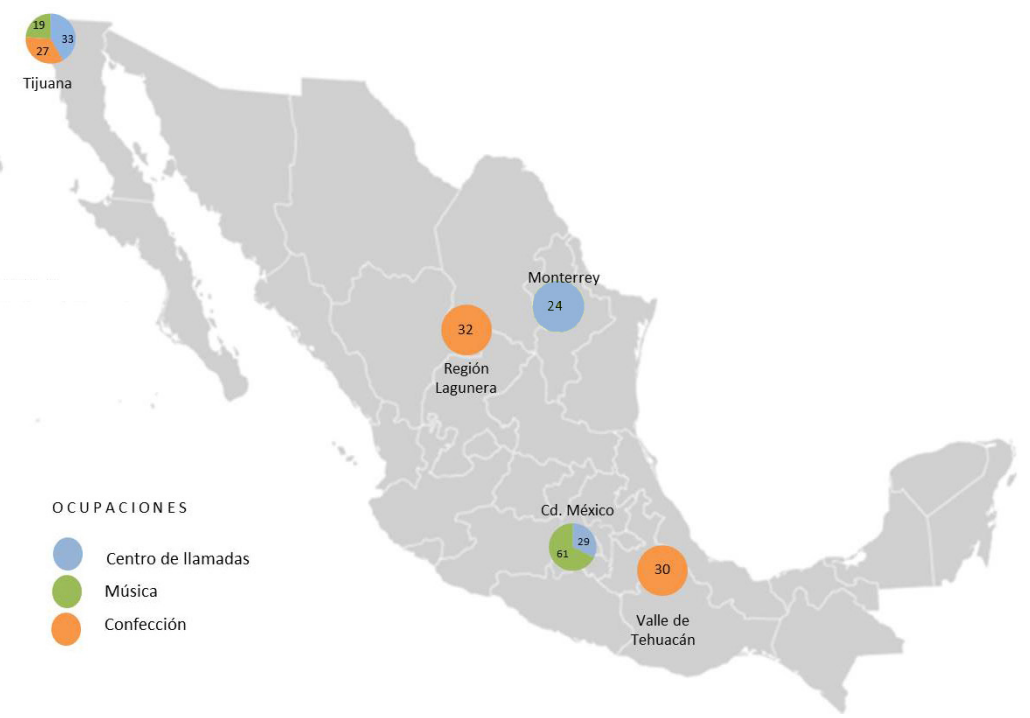

dos últimas regiones, la abundancia de mano de obra y las facilidades otorgadas para la instalación de la industria contribuyeron al boom que tuvo lugar en la década de 1990. Sin embargo, las políticas de flexibilidad laboral y las sucesivas crisis económicas a partir de 2001 cambiarían el curso de su desarrollo. Este último factor se manifestó en la drástica disminución del empleo, la caída de los salarios y la pérdida de prestaciones para los trabajadores, que, en los tiempos de auge, habían tenido la opción de elegir en qué empresas trabajar (Bair y Gereffi, 2003; Martínez de Ita et al., 2005). Los cambios en la historia reciente se pueden apreciar con mayor claridad en este sector, en el que los efectos del auge y la caída posterior del empleo afectaron de manera opuesta a las prestaciones laborales de dos generaciones de trabajadores.

En contraste, la expansión de los centros de atención de llamadas en México se da a partir de los años noventa como parte de un fenómeno global en el cual la tecnología especializada en la distribución de llamadas por computadora permite vender productos o prestar servicios privados o públicos casi en cualquier actividad económica y social. El centro de atención de llamadas es un fenómeno urbano en crecimiento, con algunos altibajos en los periodos de crisis, que se localiza principalmente en grandes ciudades como México, Guadalajara Monterrey y también en Tijuana. Sin embargo, en contraste con lo expuesto para la industria de la confección, no tenemos un relato «histórico» que diferencie etapas, giros y crisis en este sector?.

9. Micheli (2012: 93 y s.) reconstruye los orígenes del marketing telefónico y algunos hitos de su evolución para la ciudad de México. 
Por último, la actividad de los músicos profesionales se concentraba, hasta principios del siglo XXI, en la ciudad de México y en unos pocos estados de la región central del país, donde trabajaban siete de cada diez de ellos. Nos referimos particularmente a los músicos de orquesta y a los profesores universitarios. Esta distribución que refleja la enorme centralización de las instituciones culturales en el país se ha modificado ligeramente, ya que, en referencia a la actividad musical, sobresalen otras entidades hoy en día, como Jalisco y Michoacán, en el occidente del país, y Nuevo León, en el noreste. Por su parte, la región noroeste, de la que forma parte Tijuana, ciudad incluida en este estudio, muestra un desarrollo incipiente y empiezan a despuntar algunos centros de formación profesional, así como orquestas locales y compañías de espectáculos. La apertura de estos nuevos mercados de trabajo es fuente inicial de oportunidades de empleo, aunque no necesariamente comporten buenas condiciones laborales (Guadarrama, 2013).

\section{La heterogeneidad del tejido productivo y de la organización laboral}

Tanto en la industria de la confección como en los centros de atención de llamadas, la organización tiene una influencia fundamental. La confección forma parte de una cadena productiva global integrada por empresas subsidiarias y subcontratistas nacionales y extranjeras, en tanto que los centros de atención de llamadas se caracterizan por procesos de subcontratación (outsourcing), con una amplia variedad de cadenas de valor.

En la confección, la cadena productiva global la conforman empresas de distintos tamaños en relación de subcontratación: las transnacionales organizan la cadena en la cual los procesos de subcontratación presentan un orden jerárquico que pasa por las pequeñas y medianas empresas hasta los talleres a domicilio. Estas diferencias en el tamaño de las empresas propician la formación de segmentos de trabajadores con distintos grados de precariedad en cada región, siendo las grandes empresas transnacionales las que generalmente ofrecen salarios y condiciones laborales mejores. De las tres regiones consideradas, estas últimas empresas se concentran en la Región Lagunera y el Valle de Tehuacán; las medianas, en la Región Lagunera y en Tijuana; en tanto que los pequeños talleres proliferan en el Valle de Tehuacán. En las tres regiones, se observan procesos de subcontratación.

De manera similar, en los centros de atención de llamadas los perfiles de la mano de obra y sus condiciones de trabajo son distintos. En los centros de atención de llamadas internos (in house) ${ }^{10}$, donde el nivel de escolaridad es más alto, las condiciones son más favorables que en los centros subcontratados, porque los operarios, generalmente, tienen condiciones laborales semejantes a las del resto de los trabajadores ${ }^{11}$.

10. Este tipo de centro de atención de llamadas está formado por secciones o departamentos de las empresas que dan servicios a sus clientes.

11. Sin embargo, en esta investigación, esta diferencia se observó únicamente en algunas trayectorias de la ciudad de Monterrey, tal vez porque en las otras ciudades de estudio se entrevistó principalmente a trabajadores de centros de atención de llamadas de subcontratación (outsourcing). 
En el caso de los músicos, las grandes compañías de espectáculos y las orquestas se concentran en el Distrito Federal, aunque las regiones emergentes como Tijuana están adquiriendo mayor relevancia. Sin embargo, la masificación de la enseñanza y la concentración incrementan las diferencias regionales. En todo caso, es en las orquestas más firmemente establecidas, públicas y con subsidios permanentes, así como en las universidades, en donde encontramos los segmentos de profesionales más estables y con mejores condiciones de trabajo.

\section{Tipos de trayectorias por ocupación}

El punto de partida de esta investigación se relaciona con la idea de que, para entender la complejidad procesual de la precariedad y sus particularidades en cada ocupación, es necesario seguir un procedimiento que considere la relación entre las múltiples condiciones objetivas y subjetivas de vida y trabajo de los individuos. De acuerdo con esta orientación, para elaborar las trayectorias laborales, tomamos en cuenta, en primer lugar, los elementos objetivos identificados en el cuestionario, tales como el inicio, la cantidad y la duración de los eventos. Estos criterios nos permiten analizar de forma comparativa las trayectorias laborales y descubrir los rasgos semejantes de la precariedad, a la vez que muestran la heterogeneidad y las marcas distintivas del fenómeno en cada una de las tres ocupaciones consideradas, de acuerdo con su contexto histórico-social, el tipo de empresas en que laboran los trabajadores y sus propias características individuales ${ }^{12}$. Este ejercicio nos permite demostrar la heterogeneidad de la precariedad, que adquiere formas diversas según la ocupación y el contexto histórico y biográfico de los individuos. Para documentar este último, nos valimos de los datos derivados de las entrevistas.

El primer resultado importante de este análisis es que la inestabilidad y la incertidumbre en el empleo, que dificultan la acumulación de saberes en una sola ocupación, son dos aspectos que aparecen de manera recurrente en la mayor parte de las trayectorias. Ello se observa incluso en aquellas con relativa estabilidad, como las de algunos músicos sin contrato pero con permanencia prolongada en orquestas, que viven en la incertidumbre. Lo mismo se encuentra en los trabajadores de la confección con una larga trayectoria en una empresa, que no los exime del riesgo, cada vez más frecuente, de ser despedidos. A veces son estos trabajadores con trayectoria aparentemente más estable los que viven con mayor estrés la inseguridad en el empleo.

Estos rasgos generales quedan matizados por las particularidades de las trayectorias en cada ocupación que describimos y analizamos a continuación (véase más abajo el cuadro 1 sobre tipos de trayectorias). En este sentido, la tipología por ocupación constituye una síntesis analítica de las tendencias observadas a través de los datos cuantitativos y de los casos individuales caracterizados por medio de las entrevistas.

12. Santamaría (2012) propone una tipología que incluye tanto aspectos objetivos como subjetivos y la continuidad o discontinuidad de la trayectoria. 
En el sector de la confección, se encontraron cinco tipos de trayectorias. En primer lugar, aquellas que denominamos sectoriales, porque los trabajadores han desarrollado la mayor parte de su vida laboral en la confección. Sin embargo, la permanencia prolongada en el mismo sector puede darse al menos de dos formas que revelan una capacidad de agencia diferente. Se encuentra, por un lado, una trayectoria itinerante precarizada, en la cual los eventos laborales en varias empresas son forzados por recortes, despidos o malas condiciones de trabajo que obligan al trabajador a rotar entre empresas sin que sus condiciones laborales experimenten mejoras. Una segunda trayectoria sectorial es la que hemos denominado itinerante flexible, que se da entre aquellos trabajadores que también han vivido experiencias en varias empresas de la confección, pero los cambios entre empresas son voluntarios en busca de mejores condiciones de trabajo.

Otro tipo de trayectorias son las que están ligadas a la permanencia prolongada en una sola empresa. Sin embargo, no todas las trayectorias de empresa se desarrollan de la misma manera, ni obtienen el mismo resultado. En algunos casos, se produce lo que denominamos trayectoria de ascenso difuso por formación y capacitación, porque se da en secuencias donde se perciben avances y retrocesos sin una dirección clara. Una segunda trayectoria es de claro ascenso hacia puestos más altos y mejores condiciones laborales. Finalmente, encontramos una trayectoria de empresa en riesgo, que es la de aquellos trabajadores de mayor edad cuya trayectoria larga en una empresa no les garantiza un futuro asegurado ni una jubilación decente.

Además de las trayectorias donde predominan los empleos en el sector, se detectan otras, todavía más precarias, que se desarrollan fuera del mismo. Distinguimos tres subtipos: las de quienes trabajan en talleres a domicilio, las trayectorias discontinuas en distintos sectores de actividad y las trayectorias de desempleo recurrente. El trabajo a domicilio para un taller es una modalidad de subcontratación que se caracteriza por la percepción de ingresos irregulares y la inexistencia de beneficios sociales. En las trayectorias discontinuas, los trabajadores alternan actividades laborales en otros sectores y en la propia industria de la confección, donde la ventaja principal son las prestaciones sociales. En algunas de ellas, se encuentran periodos de desempleo frecuente ${ }^{13}$.

Como se observa, pocas trayectorias traslucen un recorrido firme de mejora sostenida. Son mucho más frecuentes aquellas afectadas por coyunturas difíciles, con desempleo y recortes de personal, o bien las que podemos denominar trayectorias estructuralmente precarias, como las de aquellos trabajadores sumidos de manera recurrente en el desempleo o los que trabajan en los talleres a domicilio.

El empleo en centros de atención de llamadas, a diferencia de la confección, carece de una «memoria histórica» en la cual las políticas de flexibilidad o las

13. Este es un fenómeno a destacar, puesto que el desempleo abierto en México es relativamente bajo (entre un $5 \%$ y un $6 \%$ de la PEA), pues la inexistencia de un seguro de desempleo impulsa a los trabajadores a buscar actividades informales de subsistencia. 
crisis puedan interpretarse como hitos importantes para las trayectorias de los trabajadores. Las referencias al contexto en las entrevistas aluden principalmente a la inestabilidad derivada de la finalización de "campañas» específicas ${ }^{14}$, de la incertidumbre que surge en los procesos de subcontratación y del traslado eventual de ciertos procesos a empresas de otras ciudades o países.

Estos cambios se pueden dar incluso aunque el trabajador tenga posibilidades de ascender en la empresa. De ahí que, en los centros de atención de llamadas, predominen las trayectorias mixtas, que comienzan en el comercio o en los servicios y que, a partir de cierta etapa, continúan en un centro de atención de llamadas. Si bien es cierto que algunos de los que aceptan un empleo en los centros de atención de llamadas buscan los horarios flexibles o de tiempo parcial para seguir estudiando, también se encontró un grupo importante de trabajadores, especialmente en el Distrito Federal, que, habiendo concluido su carrera universitaria, se asientan en un centro de atención de llamadas. La mayor ventaja percibida por estos trabajadores, en comparación con otros empleos posibles, es el acceso a prestaciones sociales y horarios flexibles o de tiempo parcial. En este tipo de trayectorias, se encuentran también casos extremos de inestabilidad constante, en trabajos precarios y de corta duración.

En las trayectorias mixtas, un subtipo interesante que no había sido analizado en otras investigaciones relativas a este sector de ocupación es el de las trayectorias tardias. Se trata de hombres y mujeres que, en su edad madura o en la última fase de su vida laboral, empiezan a trabajar en un centro de atención de llamadas por distintos motivos: algunos porque fueron deportados de Estados Unidos, otros fueron despedidos o, en el caso de las mujeres, porque se incorporan tardíamente al mercado de trabajo ${ }^{15}$. La mayor parte de sus testimonios reflejan la incertidumbre ante sus opciones de jubilación y, en los deportados, la ausencia de redes familiares y sociales.

En los centros de atención de llamadas, al igual que en el sector de la confección, encontramos algunos casos de trayectorias de empresa: se trata de trabajadores que logran ascender a puestos de supervisor, capacitador y gerencias de recursos humanos en los cuales obtienen mejores ingresos y algunos otros beneficios. La mayor parte de ellos dicen que hacen «lo que les gusta», pero, para algunos, el trabajo en un centro de atención de llamadas sigue siendo poco satisfactorio a pesar de estos ascensos. Un subtipo de trayectoria de empresa es el que se produce sin ascenso de puesto, sino únicamente mediante el logro de un salario más alto o la mejora en otras condiciones de trabajo.

14. La «campaña» se refiere a una actividad con un límite temporal relacionada con un producto o un proyecto, como, por ejemplo, una encuesta política, que el centro de atención de llamadas lleva a cabo en función de lo que dure el contrato.

15. En el sector de la confección, se encontraron talleres pequeños que ocupan a mujeres de edad madura que, por necesidad, se reincorporan al mercado de trabajo y que, por su edad, no consiguen empleo en las empresas de mayor tamaño. Los talleres parecen ser el refugio de este perfil de trabajadoras de la confección. Entre los músicos, el trabajo por cuenta propia, como maestras particulares, es el refugio tradicional de las mujeres maduras. 
Finalmente, hallamos un tercer tipo de trayectoria, que denominamos trayectoria sectorial, en la cual los trabajadores únicamente se han empleado en este tipo de trabajo, ya sea en una sola empresa o en varias. En este último caso, se observa la creación de redes sociales que facilitan la rotación entre empresas y una suerte de conocimiento informal compartido acerca de las características del mercado laboral.

En resumen, las trayectorias en centros de atención de llamadas son un ejemplo de la incertidumbre que rodea el empleo de los jóvenes en el México contemporáneo, incluso para aquellos que, como los operarios de centros de atención de llamadas, han estudiado bachillerato o una carrera. Pero, como se analizó más arriba, el empleo en los centros de atención de llamadas no se limita a los jóvenes. Los trabajadores de entre 30 y 40 años valoran dicha ocupación por las prestaciones sociales, aunque otras condiciones laborales sean precarias. En contraste, para las personas mayores, este tipo de empleos parece una suerte de «mal menor» después de un fuerte viraje o una ruptura negativa (turning point) en su carrera profesional y en su vida personal. Es lo que ocurre en el caso de los trabajadores mexicanos deportados de Estados Unidos o de ciertos profesionales despedidos de sus empleos en tiempos de crisis.

Por último, veamos el caso de los músicos. Estos profesionales presentan ciertas particularidades que los diferencian de las otras dos ocupaciones, aunque la inestabilidad, la precariedad y la incertidumbre están presentes en la mayor parte de los casos estudiados aun entre los supuestamente más estables, como los músicos de orquesta. Para destacar estas diferencias, antes de describir sus trayectorias, es preciso detenerse brevemente en algunos de los rasgos que distinguen a esta profesión creativa por vocación.

En primer lugar, se observa una suerte de itinerario ideal o trayectoria de referencia a partir de cierta etapa en la vida profesional de los músicos, que supone una adecuación estrecha entre el diploma y el empleo al que se aspira. Esta trayectoria ideal se sustenta en un proyecto profesional relativamente coherente, que se construye por medio de una estrategia sostenida en la formación y en la superación permanentes y que se traduce en una serie de acciones conscientes que tienen como objetivo el éxito personal. Estas características, que pueden variar de un contexto a otro, han dominado por años el imaginario social de esta profesión en México, por lo que es posible hablar de un modelo de empleo característico de este tipo de músicos. El punto de estabilidad de esta trayectoria ideal se obtiene en la etapa de madurez profesional, alrededor de los 40 años. Dicho modelo se observa tanto en los músicos de orquesta - donde hay una fuerte presencia de músicos extranjeros - como entre los profesores de más alto rango de las instituciones de educación superior. Este tipo de trayectoria de referencia no se da en ninguna de las otras dos ocupaciones no profesionales. En el caso de los músicos de orquesta, como ya se dijo, se trata de proyectos individuales inspirados en un ideal profesional fuertemente interiorizado a lo largo de una formación de muchos años que desemboca en estrategias diversas de ingreso al mercado de trabajo y de promoción profesional. En la medida en que las trayectorias se alejan de este itinerario ideal, encontramos otros tipos más o menos precarios. 
El segundo tipo de trayectoria observada corresponde a los músicos con estabilidad precaria y empleos secundarios de subsistencia. Es importante subrayar aquí que la estabilidad no es una condición suficiente para evadir la precariedad, como ocurre en la trayectoria de riesgo en el sector de la confección o incluso entre algunos trabajadores con una permanencia relativamente larga en los centros de atención de llamadas. Este fenómeno se intensifica particularmente en aquellas trayectorias con cierta discontinuidad, en las que los músicos tienen trabajos de tiempo determinado, eventual e intermitente. Este es el caso de los músicos temporales en las orquestas e incluso de los semipermanentes de aquellas orquestas con menor solidez financiera y profesional, que carecen de contratos y prestaciones, así como de los maestros contratados a tiempo parcial en los diversos establecimientos de iniciación y formación profesional.

La tercera trayectoria se caracteriza por ser de precariedad acumulada. En ella, se suman los empleos temporales, la multiactividad en ocupaciones por proyecto o por eventos y los cambios continuos en el empleo en un entorno de precariedad donde los trabajos se aceptan más por necesidad económica que como un medio de realización profesional. Sin embargo, resulta interesante señalar que algunos pocos músicos consiguen revertir esta situación incursionando en otros géneros musicales fuera de las orquestas, como el jazz, en donde logran impulsar proyectos musicales que eventualmente son exitosos y les permiten construir carreras creativas diversificadas aunque no seguras. Estos giros o rupturas positivas (turning point) se dan principalmente entre profesionales de clase media que usan sus redes sociales y desarrollan carreras autogestionadas en la industria cultural y proyectos financiados por el Estado. En el caso de los músicos de origen popular, muchos de ellos maestros de educación secundaria con contratos indefinidos con bajos salarios, esta estabilidad precaria da un giro, esta vez negativo, en la etapa de la jubilación hacia la multiactividad obligada por las bajas pensiones.

\section{Elementos secuenciales de la precariedad}

La descripción y los análisis objetivos de las trayectorias laborales, en cada una de las ocupaciones estudiadas, demuestra claramente que el mercado de trabajo mexicano ofrece pocas oportunidades de estabilidad y mejoría laboral y profesional y que no resulta fácil superar estos condicionamientos. Sin embargo, más allá de esta conclusión general, basada en la observación de las diferencias entre ocupaciones y sus particularidades, en esta investigación intentamos también reconocer sus elementos comunes. Para ello, se consideran las secuencias de los eventos laborales que permiten examinar los procesos de precarización a lo largo de la vida de las personas (véase cuadro 1).

\section{Secuencias y grados de precariedad}

En esta propuesta analítica, las secuencias de los eventos laborales son el eje que da estructura a las trayectorias y a los procesos de precarización, de ahí 
Cuadro 1. Las trayectorias laborales comparadas

\begin{tabular}{|c|c|c|c|}
\hline & \multicolumn{3}{|c|}{ Elementos del contexto } \\
\hline & Confección & $\begin{array}{l}\text { Centros de atención } \\
\text { de llamadas }\end{array}$ & Músicos \\
\hline & $\begin{array}{l}\text { Históricos. } \\
\text { Crisis económicas. } \\
\text { Políticas de flexibilidad. } \\
\text { Estructura de la industria: } \\
\text { - Grandes empresas } \\
\text { y Pymes. } \\
\text { - Región. }\end{array}$ & $\begin{array}{l}\text { Deslocalización de los } \\
\text { negocios. } \\
\text { Tipo de centro de } \\
\text { atención de llamadas } \\
\text { (interno o subcontratado). } \\
\text { Contexto urbano (ciudad). }\end{array}$ & $\begin{array}{l}\text { Centralización de la } \\
\text { infraestructura cultural y } \\
\text { de las oportunidades de } \\
\text { empleo. } \\
\text { Hiperflexibilización } \\
\text { y multiactividad. } \\
\text { Segmentación de } \\
\text { los mercados. }\end{array}$ \\
\hline & \multicolumn{3}{|c|}{ Secuencias y grados de precariedad } \\
\hline Mínima & $\begin{array}{l}\text { Trayectoria de empresa: } \\
\text { - Con ascenso difuso. } \\
\text { - Con ascenso claro. }\end{array}$ & $\begin{array}{l}\text { Trayectoria de empresa: } \\
\text { - Con ascenso. } \\
\text { - Sin ascenso pero con } \\
\text { mejora salarial. }\end{array}$ & $\begin{array}{l}\text { Trayectoria ideal } \\
\text { o de referencia. }\end{array}$ \\
\hline Media & $\begin{array}{l}\text { Trayectoria sectorial: } \\
\text { - De riesgo. } \\
\text { - Itinerante precaria. } \\
\text { - Itinerante flexible. }\end{array}$ & $\begin{array}{l}\text { Trayectoria sectorial: } \\
\text { — Trayectoria en } \\
\text { centro de atención } \\
\text { de llamadas. }\end{array}$ & $\begin{array}{l}\text { Trayectoria con estabilidao } \\
\text { precaria y empleos de } \\
\text { subsistencia. }\end{array}$ \\
\hline Máxima & $\begin{array}{l}\text { Trayectorias estructu- } \\
\text { ralmente precarias: } \\
\text { - En domicilio. } \\
\text { - Discontinua. } \\
\text { - Con desempleo } \\
\text { recurrente. }\end{array}$ & $\begin{array}{l}\text { Trayectoria mixta: } \\
\text { - Trayectoria tardía. }\end{array}$ & $\begin{array}{l}\text { Trayectoria de precariedad } \\
\text { acumulada. }\end{array}$ \\
\hline
\end{tabular}

Fuente: elaboración propia a partir de la encuesta Heterogeneidad ocupacional, precariedad laboral y diferencias de género en México. Proyecto 83530-Conacyt Ciencia Básica.

que tenga una mayor importancia que otras dimensiones procesuales. Bajo este criterio, las trayectorias se clasifican según los tres grados de precariedad observados: mínima, media y máxima.

En el grado de precariedad mínima, ubicamos las trayectorias de empresa de la confección y los centros de atención de llamadas, además de las trayectorias con estabilidad y proyecto profesional entre los músicos profesionales. En este grado, las condiciones de trabajo son buenas y hay ciertas garantías de estabilidad, mayores para los músicos que para los trabajadores de las otras dos ocupaciones.

El grado de precariedad medio se encuentra sobre todo en aquellas trayectorias sectoriales donde una cierta estabilidad no impide que se den condiciones de precariedad relativa. Es lo que aparece en las trayectorias sectoriales de la confección y en centros de atención de llamadas - aunque la estabilidad en este sector es generalmente muy dudosa- y entre los músicos semipermanentes 
que compaginan un trabajo principal con relativa estabilidad en las orquestas con empleos de subsistencia.

El grado de precariedad alto se encuentra en las trayectorias con empleos fuera del sector. Esto resulta claro en la confección para las trayectorias de las mujeres que se desarrollan como trabajadoras a domicilio en los talleres de costura, en las trayectorias discontinuas y aquellas marcadas por el desempleo recurrente. Lo mismo ocurre entre los músicos que tienen trayectorias con permanencia discontinua y precariedad acumulada, aunque, como ya se dijo antes, entre ciertos músicos, puede darse un giro positivo que les permite acceder a mejores empleos aún fuera de su sector. Ello significa que esas trayectorias no son irreversibles. En el caso de los centros de atención de llamadas, resulta arriesgado establecer una línea divisoria tajante entre el nivel medio y el nivel bajo de la precariedad en relación con la tipología de trayectorias. Tanto en las trayectorias mixtas como en las trayectorias sectoriales en centros de atención de llamadas, encontramos ejemplos tanto de una precariedad acentuada como de una precariedad atemperada por la oportunidad de obtener un ingreso relativamente alto o la posibilidad de percibir prestaciones sociales.

\section{Trayectorias, subjetividad y agencia}

Hasta aquí, la tipología de trayectorias se basa en una identificación objetiva de los itinerarios entre sectores de ocupación, de los grados de precarización y de su evolución en el tiempo. Para terminar, en este último apartado, incorporamos la subjetividad de los individuos, que muestra cómo, dentro de ciertos límites estructurales y contextuales, los individuos pueden orientar sus vidas laborales en un sentido o en otro.

Como se mencionó líneas arriba, en la industria de la confección, hay que considerar un parteaguas que define la calidad de los empleos. Durante el boom de esta industria, en los años noventa, se obtenían mejores salarios (más altos que el salario mínimo) y prestaciones superiores a las básicas, como los servicios de transporte y comedor, debido a la alta demanda de trabajo en las regiones de estudio. Esta situación que ofrecía ciertas ventajas a los trabajadores se transformó con la crisis del sector. No obstante, quedó como una referencia ideal, como una aspiración posible en las trayectorias de estos trabajadores, que se puede resumir en la idea de tener un empleo con salario base garantizado y prestaciones básicas como la seguridad social y el acceso a vivienda. Se trata, por tanto, de trayectorias basadas en el logro de condiciones mínimas, en las cuales las mejoras salariales dependen del tipo de operaciones que se realizan y de la rapidez con que se llevan a cabo.

Desde el punto de vista de los actores, tomando en cuenta la situación pasada, la presente, así como sus expectativas para el futuro, su percepción de la trayectoria de referencia se transforma teniendo como resultado diversas actitudes, ya sea aceptación de las condiciones de trabajo impuestas por la flexibilidad en algunos casos; de riesgo e inconformidad en otros, y de asumir la itinerancia en el empleo como algo normal en sus vidas para otros más. 
Esta actitud de condescendencia se observa principalmente en las trayectorias de los trabajadores de mayor edad, que, en otro tiempo, fueron estables y que ahora se caracterizan por la incertidumbre, la vulnerabilidad y el riesgo, por lo que consienten las presiones para aumentar la productividad, la reducción de la jornada laboral y los descansos, y con ello aceptan también la reducción salarial, a cambio de conservar el empleo y las prestaciones básicas como el acceso a la seguridad social y la posibilidad de obtener una vivienda de interés social.

Entre algunos trabajadores, lo que destaca es la experiencia y el aprendizaje en el trabajo, desde la más básica obtenida en los talleres de confección, hasta habilidades polivalentes que obtienen en los procesos más complejos de las fábricas más grandes del vestido, y que consiste en el aprendizaje de diversas operaciones de costura, ya sea porque otros trabajadores les enseñan o porque lo aprenden mediante la práctica. La valoración de esta experiencia práctica supone también la aspiración a un mejoramiento de sus ingresos, lo cual depende también de la productividad del trabajador. Como dice un operario: «La maquiladora es un trabajo de competencia [...] si tú trabajas más, ganas más». Esta frase revela la forma en que los trabajadores han subjetivado el discurso de la productividad, que, en realidad, encubre un mayor nivel de explotación a través de la flexibilidad laboral. No obstante lo anterior, el conocimiento de múltiples operaciones de costura es un recurso que les sirve para obtener un empleo con mejor remuneración o mejores prestaciones, lo cual es prueba de su capacidad de agencia.

Para los trabajadores más jóvenes que cambian de empleo con frecuencia, ya sea por despido o por voluntad propia, la trayectoria de referencia se ha transformado en itinerancia, ya que para ellos «Eso [cambiar de trabajo con frecuencia] ya es como normal, ahorita ya no hay nada, ya no hay nada estable» (trabajadora de la confección, Tehuacán). Por una parte, esta visión es muestra de la condición laboral inestable e insegura, que no permite a los jóvenes que se emplean en esta industria visualizar un futuro, sino solamente resolver las contingencias de la vida cotidiana. Pero, por otra parte, algunos de ellos cambian de empleo porque son conscientes de sus derechos humanos, y esta idea forma parte de la visión de su futuro laboral. Otro caso es el de mujeres adultas que desarrollaron su trayectoria en alguna fábrica grande y que, al perder su empleo, también se han transformado en itinerantes y trabajan en distintas empresas a lo largo del año. Lo anterior ha sido posible gracias a su experiencia laboral, así como a la construcción de redes sociales con patrones y otros trabajadores. Su ventaja con relación a los jóvenes es, como ya se dijo, la experiencia, lo cual les permite negociar con sus patrones temporales salarios y prestaciones, y reconstruir de esta forma su proyecto laboral.

A pesar de lo anterior, los trabajadores entrevistados de mayor edad aprecian sus empleos porque han sido, y son, una fuente de ingresos para la manutención de sus familias y para la educación de sus hijos. En particular, algunas de las entrevistadas valoran su empleo porque han trabajado muchos años en el sector y se perciben a sí mismas como «maquileras». Aunque para algunas trabajadoras la costura es un oficio, para otras este sentido de identidad parece 
estar relacionado con la pertenencia a las fábricas de la confección de ropa y la diversidad de operaciones que se llevan a cabo en las líneas de ensamble.

En su conjunto, el empleo en las fábricas de la confección podría ser considerado como una oportunidad con distintos matices y restricciones según la etapa de la vida. Por ejemplo: el sector de la confección es una oportunidad para los trabajadores más jóvenes que desean independizarse de sus familias, para los que inician una vida familiar, tienen hijos pequeños y mayores responsabilidades, así como también para las mujeres adultas con opciones reducidas de trabajo, que vuelven al mercado laboral después de la crianza de los hijos. Además, las entrevistas muestran que, para algunas mujeres, el empleo en la confección no solo ha sido un medio de subsistencia, sino que también les ha permitido ejercer algún control sobre sus vidas, tomar decisiones y negociar con la pareja en la familia, así como organizarse en la fábrica por la lucha de sus derechos laborales.

En el caso de los centros de atención de llamadas, la trayectoria de referencia, desde la lectura que hacen los propios sujetos de su situación en un momento dado de sus vidas, se fundamenta en una condición de trabajo «transitorio» que surge de una combinación de la evaluación de las oportunidades en el momento presente y de las opciones de futuro (evaluación práctica y agencia proyectiva). Dado que, en el momento presente, las oportunidades de empleo no son muchas, y tomando en cuenta que el centro de atención de llamadas tiene horarios flexibles, este empleo parece la mejor opción «en tanto concluyo mis estudios universitarios». Esta estrategia funcionalista o pragmática de los jóvenes estudiantes se asume con distintos grados de satisfacción ${ }^{16}$.

Sin embargo, lo que en un principio se plantea subjetivamente como algo transitorio, en el centro de atención de llamadas comienza a alargarse por circunstancias personales (conveniencias de los horarios, trabajos de cuidado) o por las propias restricciones de los mercados de trabajo, de manera que el empleo en uno o varios centros de atención de llamadas define la trayectoria laboral. En estos casos en los que se encuentran trabajadores de diferentes edades, vemos dos tipos de respuestas: las de conformidad y las que denominamos de adaptación contestataria. En las primeras, los individuos mencionan tanto aspectos positivos como negativos del empleo en centros de atención de llamadas, pero subrayan los primeros intentando encontrar una justificación satisfactoria a su ocupación. Uno de los aspectos valorados positivamente por trabajadores de trayectorias distintas es la tarea de comunicarse con los clientes, pues, a pesar de los rígidos protocolos, pueden desarrollar habilidades de persuasión y convencimiento ${ }^{17}$. Cuando se desarrollan estrategias de adaptación contestataria, los trabajadores continúan a regañadientes en los centros de atención de llamadas a pesar de que su valoración general es negativa. En los casos de mayor inconformidad donde no hay otras opciones en el mercado de trabajo, se puede hablar de la «trampa de la precariedad»,

16. Algo similar encuentran en sus estudios de caso López-Andreu y Verd (2013).

17. Aunque, ciertamente, para otros trabajadores, la comunicación con los clientes es un motivo de estrés cotidiano insoportable. 
en la medida en que la trayectoria se prolonga en el mismo sector por miedo a perder el empleo.

Paradójicamente, en los centros de atención de llamadas, no aparece como trayectoria de referencia la trayectoria de empresa que, desde una perspectiva subjetiva, se basa en una estrategia de aprendizaje o profesionalizante. En este caso, la agencia se sustenta en una serie de conocimientos y actitudes que pueden dar lugar a círculos virtuosos o causalidades acumulativas que llevan a mejorar el ingreso con ascensos en el escalafón. Para ello, es necesario interiorizar la lógica productiva, organizativa y disciplinaria de las empresas. Este tipo de trayectorias está al alcance de individuos con determinados conocimientos (habilidades) y destrezas (gestión de personal, capacidades de negociación) que progresivamente, encuentran en su trabajo una satisfacción ligada a su realización personal. Sin embargo, algunos de estos individuos rechazan desarrollar dicho tipo de trayectoria porque no está a la altura de sus expectativas y buscan ejercer una profesión acorde con su carrera.

A pesar de los resultados obtenidos en el análisis de trayectorias, resulta problemático discernir si, en esta ocupación, se dan procesos de precarización de largo plazo. Por un lado, la trayectoria de referencia se construye sobre la idea de la transitoriedad y, por otro lado, los índices de rotación son altos. Ambos fenómenos dificultan captar continuidades y discontinuidades en periodos temporales más largos. Finalmente, los procesos de mejora o profesionalización son dudosos, porque la estructura organizativa de la mayoría de estas empresas presenta una base amplia de operadores y pocos escalones jerárquicos para construir una carrera ascendente.

Los músicos de orquesta, como ya se ha dicho, son el ejemplo de una profesión orientada por figuras de referencia fuertemente ancladas en carreras profesionales largas, que suponen saberes acumulados que aseguran la realización y el prestigio laboral, así como cierto estatus social. Esta figura de referencia influye desde muy temprano en la selección de la carrera, aunque, poco a poco, estas aspiraciones profesionales se modifican como resultado de las experiencias vividas en un mercado de trabajo hiperflexible.

Frente a la imagen ideal de referencia del músico de orquesta establecido, que se caracteriza por tener una carrera larga, producto de la combinación de estudio, disciplina y talento, surgen estrategias concebidas desde un sentimiento de incertidumbre que obliga a los músicos a matizar esta referencia ideal en medio de los avatares de un mercado de trabajo caracterizado por el multiempleo y el trabajo por proyectos.

Muchos músicos profesionales conciben su carrera como un largo camino de sacrificios familiares, sociales, económicos, por amor al arte o por vocación. Estos sacrificios, inspirados en la figura épica del artista, se ven recompensados por las remuneraciones no monetarias conseguidas a través de su formación artística (capital humano) y el prestigio adquirido a lo largo de su carrera (capital cultural). Entre estos músicos que trabajan por amor al arte y que buscan hacer carrera vinculados a ciertas orquestas, ensambles y figuras de prestigio, se encuentran los semipermanentes y los músicos amateurs que trabajan por contrato. 
Para otros músicos, desde que inician su carrera, la experiencia profesional es tan importante como los estudios. Entre quienes siguen esta estrategia de aprendizaje doble, hay quienes, finalmente, abandonan sus estudios y desarrollan carreras sostenidas únicamente en su experiencia en la práctica. Estos últimos tienen una personalidad más individualista, capaz de asumir riesgos en el mercado de trabajo, en el que pueden alcanzar éxito, pero también fracasar y quedarse desempleados por algunos periodos. Esta estrategia autogestionada corresponde generalmente a músicos jóvenes que combinan el trabajo eventual en las orquestas con empleos por cuenta propia o por contrato. Por este camino, entran en contacto con músicos que basan sus carreras en la experimentación apoyada en nuevas tecnologías y se incorporan en la industria cultural o en los circuitos de la música alternativa.

En contraste con estos músicos experimentales, aparecen los conformistas, que prefieren asegurarse un lugar estable en el mercado de trabajo, aun con bajos ingresos y pensiones raquíticas al final de su carrera, a costa de renunciar a sus aspiraciones de éxito profesional como instrumentistas. Entre estos músicos, se encuentran los profesores de escuelas públicas, principalmente localizados en los niveles de iniciación musical y estudios propedéuticos.

En resumen, podríamos decir que, en esta profesión por vocación, la incertidumbre laboral y la multiactividad es la característica más distintiva de las trayectorias de los músicos. Sin embargo, esta inestabilidad en el empleo no se traduce necesariamente en precariedad. En algunos casos, es sinónimo de versatilidad, innovación y éxito, aunque en otros implica una vida laboral incierta, sin proyecto profesional y sin logros económicos que permitan a los músicos sentirse retribuidos por los esfuerzos realizados a lo largo de su carrera. A fin de cuentas, lo que distingue a estos profesionales es el arraigo a la figura de referencia primaria, que, aunque matizada a lo largo de sus distintas trayectorias, queda como una figura ideal que les da identidad.

\section{Comentarios finales}

El análisis sobre las tres ocupaciones estudiadas en este artículo remite a características generales del mercado de trabajo mexicano que se han señalado en otras investigaciones. Una de las más importantes es que las trayectorias de los individuos y los rasgos que estas adoptan están fuertemente influidas por contextos estructurales de flexibilidad. Este rasgo agregado a la debilidad institucional de las políticas públicas (laborales y sociales), la inoperancia o ambigüedad de las regulaciones laborales y la escasa información de los propios trabajadores acerca de dichas regulaciones conforman un cuadro en el cual la individualización de las relaciones laborales es un rasgo decisivo para entender lo que ocurre en los mercados de trabajo mexicanos.

En ausencia de un soporte institucional formal, los trabajadores encuentran un cierto apoyo en las redes familiares y/o en las redes sociales en la industria de la confección. Sin embargo, la configuración actual de las estructuras familiares y sociales también muestra rasgos importantes de fragilidad y cambio 
por fenómenos complejos como la migración y otros que exceden los objetivos analíticos de este trabajo.

Las ventajas de un análisis de la precariedad comparado por ocupación y regiones, pero que pone el acento en la trayectoria biográfico-laboral del fenómeno, es que permite trascender las explicaciones más esquemáticas de tipo dualista-estructural, así como las que descansan en las aspiraciones abstractas del trabajo decente, a cambio de colocar la mirada en las contingencias de la agencia humana y las ambigüedades de los significados variables de la experiencia dentro de ciertos límites.

Una segunda consecuencia de la configuración de los mercados de trabajo y de la debilidad de las instituciones y las normas es la incertidumbre a la que cotidianamente se enfrentan los trabajadores y, en consecuencia, la dificultad para trazar estrategias duraderas y proyectos de vida viables. Ello puede dar lugar, como se pudo comprobar en esta investigación, a que la "naturalización» de la inseguridad (Reygadas, 2011: 302) esté cada vez más extendida entre determinados grupos de trabajadores que se debaten entre el consentimiento y la adaptación, y la resistencia y el autoemprendimiento creativo.

La inestabilidad y la incertidumbre provienen no solo de los entornos laborales inmediatos, de las políticas de las empresas o del (in)cumplimiento de la ley en los lugares de trabajo, sino que los fenómenos de orden internacional derivados de la inserción de los sectores y las empresas en entornos globales son también una fuente importante de inestabilidad, como se vio para la industria de la confección y en el caso de los centros de atención de llamadas.

Si tanto los entornos inmediatos como los globales favorecen la precariedad en sus diferentes dimensiones, las capacidades de agencia de los individuos se reducen, pero no desaparecen del todo. En la descripción de las trayectorias, se advierte que la formación en general y la experiencia acumulada de trabajo son herramientas que, en determinados contextos, ayudan a evitar o paliar la precariedad. Esta combinación de formación y experiencia profesional es una de las estrategias más evidentes entre los músicos, en donde la formación se construye a lo largo de la trayectoria. La formación también tiene un papel entre los operarios de centros de atención de llamadas, pues, a pesar de la devaluación de los títulos universitarios, los estudios de este nivel todavía representan una posibilidad para que la trayectoria en centros de atención de llamadas sea «transitoria» y no definitiva o para ascender en las empresas. Incluso en la confección, donde la precariedad se manifiesta en múltiples dimensiones, el trabajo de campo permitió mostrar trayectorias con una mejora en las condiciones laborales, gracias al nivel educativo y al aprendizaje en la práctica. Y aún en el caso de las trayectorias inestables y las itinerantes, los trabajadores usan sus conocimientos, su experiencia laboral y otros recursos como las redes sociales para negociar sus condiciones de trabajo y reconstruir sus trayectos laborales. En este sentido, podemos afirmar que la precariedad es reversible o se puede atenuar en ciertas circunstancias.

Otros elementos sobre los que se construye la capacidad de agencia reflejan una aceptación de las reglas de juego, tanto de las empresas como de los 
mercados en general. Las trayectorias de empresa en la confección y en los centros de atención de llamadas, e incluso el ascenso en ciertas orquestas, están condicionados por el acatamiento de la disciplina ${ }^{18}$; en el centro de atención de llamadas y en la confección, por el cumplimiento de metas de productividad, y, en general, por una interiorización de los valores y los objetivos de las empresas. De la misma manera, la decisión de ciertos músicos de emprender proyectos por su cuenta o de convertirse en empresarios pone en juego su creatividad y su audacia, pero, al mismo tiempo, les obliga a aprender las normas del mundo de los negocios y del mercado.

La adaptación a estos entornos cambiantes resulta más difícil en la medida en que ciertas condiciones de diferenciación de los trabajadores, como ser mujer o superar cierta edad, se convierten en motivos de discriminación en el mundo laboral. No es casual la presencia mayoritaria de las mujeres entre los operarios en las fábricas de confección, o su especialización en ciertas filas de los instrumentos de la orquesta, o la incertidumbre que supone para los trabajadores de mayor edad de los centros de atención de llamadas un futuro incierto, debido, por un lado, a la posibilidad de un despido prematuro y, por otro, a que los planes de retiro son, en el mejor de los casos, confusos. Este tipo de planes y otras normas, como los contratos o el acceso al Seguro Social, con frecuencia, reflejan la interpretación arbitraria por parte de las empresas de las leyes laborales, así como también el desconocimiento de las mismas por parte de los trabajadores.

Los resultados de esta y otras investigaciones remiten nuevamente a la pregunta más general de la duración de la precariedad y, en consecuencia, de su reversibilidad. La situación en México en las últimas dos décadas refleja una suerte de estancamiento de algunos indicadores con avances y retrocesos coyunturales. Ello refuerza la idea de que la precariedad y la flexibilidad consentidas por las instituciones laborales, y reforzadas por la débil presencia de los sindicatos, es un fenómeno difícilmente reversible. Sin embargo, las experiencias de otros países latinoamericanos en la primera década del siglo xxI indica que hay al menos ciertos márgenes de mejora para que el mercado de trabajo se rija por la lógica del empleo formal y no por la de los trabajos precarios. Desde luego, que la construcción de nuevos esquemas generalizables de lo que debería ser hoy día el empleo formal exige todavía enormes esfuerzos de imaginación, cambios en distintas políticas y compromisos de los distintos actores nacionales, regionales e internacionales. Estos son requisitos indispensables para enfrentarse a antiguos problemas relacionados con la informalidad y la pobreza - extendida y reconstituida entre amplias capas de las sociedades latinoamericanas-, y los problemas más nuevos provocados por la globalización y el cambio tecnológico. Un viraje en esta dirección requiere, evidentemente, de la participación activa de los propios trabajadores, desde sus propias particularidades y sus propios saberes.

18. Castillo y López Calle (2007) subrayan que la importancia de las actitudes frente a las aptitudes se traduce en un reforzamiento y en una interiorización de la disciplina laboral. 


\section{Referencias bibliográficas}

Barrios Hernández, Martín y Hernández, Rodrigo Santiago (2004). Tehuacán: Del calzón de manta a los blue jeans. Toronto: Comisión de Derechos Humanos y Laborales del Valle de Tehuacán. Red de Solidaridad de la Maquila.

BAyón, Cristina (2006). «Precariedad social en México y Argentina: tendencias, expresiones y trayectorias nacionales». Revista de la CEPAL, 88, 133-152.

Bair, Jennifer y Gereffi, Gari (2003). «Los conglomerados locales en las cadenas globales: la industria maquiladora de confección en Torreón, México». Comercio Exterior, 53 (4), 338-355.

Bensusán, Graciela y Middlebrook, Kevin (2013). Sindicatos y políticas en México: Cambios, continuidades y contradicciones. México: UAM, CLACSO y FLACSO.

Bidart, Claire; Longo, María Eugenia y Mendez, Ariel (2013). «Time and process: An operational framework for procesual analysis». European Sociological Review [en línea], Oxford University Press, 29 (4), 1-13. $<$ http://dx.doi.org/10.1093/esr/jcs053>.

BidART, Claire y CATHEL, Kornig (2014). «Normes, variations et bifurcations: Analyse de figures et de trajectoires de référence au long de parcours d'insertion professionnelle». En: 14è Journées Internationales de Sociologie du Travail, Lille, 17-19 de junio.

Boudy, Jean-François (2009). Vivre de deux métiers: La pluriactivité. París: L'Harmattan.

Самасно, Fernando (2001). "La industria maquiladora en Aguascalientes 19901999». En: Quintero, Cirila y De la O, María Eugenia (coords.). Globalización, trabajo y maquilas: Las nuevas y viejas fronteras en México. México: CIESAS, Plaza y Valdez Editores, Friedrich Ebert Stiftung.

CASTEL, Robert (1997). La metamorfosis de la cuestión social. Una crónica del salariado. Buenos Aires: Paidós, Estado y Sociedad.

CAstel, Robert (2009). La montée des incertitudes: Travail, protections, statut de l'individu. París: Éditions du Seuil.

Castilla, Beatriz y Torres, Beatriz (2009). «Del hogar a la fábrica: Trabajadoras de las empresas trasnacionales en Yucatán, México». Travaux et Recherches dans les Amériques du Centres, 55, 31-52.

Castillo, Juan José y López Calle, P. (2007). «Una generación esquilmada: Los efectos de las Reformas Laborales en la vida y trabajo de los jóvenes madrileños». Sociedad y Utopía: Revista de Ciencias Sociales, 29, 293-311.

Clert, Carine (1997). «El enfoque de exclusión social: Elementos analíticos y aportaciones para la discusión sobre la pobreza y el desarrollo social en América Latina». Pensamiento Iberoamericano, 31, 425-436.

De la O, María Eugenia (2006). «Trasnacionales, trabajo y género». Desacatos, 21, 83-94

Emirbayer, Mustafa y Mische, Ann (1998). «What is agency?». The American Journal of Sociology [en línea], 103 (4), 962-1023. <http://www.ssc.wisc.edu/ - emirbaye/ Mustafa_Emirbayer/ARTICLES_files/what\%20is\%20agency.pdf> [Consulta: 30 diciembre 2014].

ESOPE (2005). A comparative study of labor market related risks in flexible economies. Bruselas: European Commission.

García GuZmán, Brígida (2006). «La situación laboral precaria: Marcos conceptuales y ejes analíticos pertinentes». Trabajo, 2 (3), 22-51. 
Garcia, Brígida (2011). «Las carencias laborales en México: conceptos e indicadores». En: Pacheco Edith; De la Garza, Enrique y Reygadas, Luis (coords). Trabajos atípicos y precarización del empleo. México DF: El Colegio de México.

- (2012). "Precariedad laboral y desempleo en México». En: Garza, Enrique de la (coord.). La situación del trabajo en México 2012: El trabajo en la crisis [en línea]. México: Universidad Autónoma Metropolitana y Valdés Editores. <http://biblio. juridicas.unam.mx/libros/8/3538/10.pdf> [Consulta: 30 diciembre 2014].

García, Brígida y Oliveira, Orlandina de (2001). «El mundo del trabajo: Heterogeneidad laboral y calidad de los empleos en las principales áreas urbanas de México». Revista Latinoamericana de Estudios del Trabajo, 7 (14), 145-164.

Gereffi, Gary; Martínez, Martha y Bair, Jennifer (2002). «Torreón: The New Blue Jeans Capital of the World». En: Gereffi, Gary; Spener, David y BAIR, Jennifer (eds.). Free Trade and Uneven Development: The North American Apparel Industry after NAFTA. Filadelfia: Temple University Press.

Guadarrama Olivera, Rocío (2013). «Mercado de trabajo y geografía de la música de concierto en México». Espacialidades, 3 (2), julio-diciembre.

Guadarrama, Rocío; Hualde, Alfredo y López, Silvia (2014) (coords.). La precariedad Laboral en México: Dimensiones, dinámica y significados. Tijuana: El Colegio de la Frontera Norte; Ciudad de México, D. F.: Universidad Autónoma Metropolitana-Cuajimalpa.

Holman, D.; Batt, R. y Holtgrewe, U. (2007). The Global Call Center Report: International Perspectives on Management and Employment. Nueva York: Report of the Global Call Center Network.

INEGI (2014). Boletín de Prensa No. 490. Resultados de la Encuesta Nacional de Empleo

Urbano. México.

Lanciano-Morandat, Caroline; Nohara, Hiroatsu y Tchobanian, Robert (2009). "Les centres d'appel en France: Mobilisation et mobilité des salariés face à un système hybride de travail». Economies et Sociétés. Série Socio-Economie du Travail [en línea], 43 (9), 1531-1564. <http://halshs.archives-ouvertes.fr/halshs-00433051/ PDF/Travail_en_centres_d_appel_francais.pdf>.

LaUtier, Bruno (1999). "Por una sociologia da heterogeneidade do trabalho». Revista Latinoamericana de Estudios del Trabajo, 5 (9), 7-32.

López-Andreu, Martí y Verd, Joan Miquel (2013). «Employer strategies, capabilites and career development: Two cases studies of Spanish service firms». International Journal of Manpower [en línea], 34 (4), 345-361. <http://dx.doi.org/10.1108/ijm-05-2013-0094>.

Lozares, Carlos y Miguélez, Fausto (2007). «De la flexibilidad del tiempo productivo a la rigidez del tiempo reproductivo». En: Prieto, C. (ed.). Trabajo, género y tiempo social. Madrid: Hacer / Complutense.

Marshall, Adriana (1996). «Empleo público en América Latina después de las Reformas del Estado». Revista Latinoamericana de Estudios del Trabajo, 2 (2), 49-76.

Martínez de Ita, María Eugenia; Sánchez, Germán y Campos, Guillermo (2005). "La industria maquiladora de exportación en el estado de Puebla». En: Garza Toledo, Enrique de la (ed.). Modelos de producción en la maquila de exportación: La crisis de Toyotismo Precario. México: UAM, Plaza y Valdez Editores.

Micheli, Jordy (2006). «El trabajo en la sociedad de la información: El caso ilustrativo del telemercadeo». Estudios Sociológicos, 24 (70), 197-220.

Micheli Thirión, Jordy (2012). Telemetrópolis: Explorando la ciudad y su producción inmaterial. México: Gedisa/UAM-Azcapotzalco. 
Miker, Martha C. (2001). "Globalización, TLCAN y crecimiento de la industria maquiladora del vestido en Sonora». En: De la O, M. Eugenia y Quintero, Cirila (coords.). Globalización, trabajo y maquilas: Las nuevas y viejas fronteras en México. México: CIESAS / Plaza y Valdez Editores / Friedrich Ebert Stiftung.

Newman, Isadore y Benz, Carolyn r. (1998). Qualitative-Quantitative Research Mtehodology. Exploring the Interactive Continuum. Carbondale/Edwarsville: Southern Illinois University Press

OIT (2014a). Panorama Laboral 2014. Lima: Oficina Regional para América Latina y el Caribe.

OIT (2014b). El empleo informal en México: Situación actual, politicas y desafíos. Programa de promoción de la formalización en América Latina y el Caribe (FORLAC).

Pacheco, Edith (2004). Ciudad de México heterogénea y desigual: Un estudio del mercado de trabajo. México: El Colegio de México.

Pacheco, Edith; Garza, Enrique de la y Reygadas, Luis (coords.) (2011). Trabajos atípicos y precarización en el empleo. México: El Colegio de México.

Pacheco, Edith (2014). «El mercado de trabajo en México a inicios del siglo XXI» En: Guadarrama, Rocío; Hualde, Alfredo y López, Silvia (2014) (coords.). La precariedad Laboral en México: Dimensiones, dinámica y significados. Tijuana: El Colegio de la Frontera Norte; Ciudad de México, D.F.: Universidad Autónoma Metropolitana-Cuajimalpa.

Paugam, Serge (2000). Le salarié de la précarité. París: Presses Universitaires de France.

PÉrez SaInz, Juan Pablo (2014). Mercados y bárbaros: La persistencia de las desigualdades de excedente en América Latina. San José, Costa Rica: FLACSO.

Reygadas, Luis (2011). «La experiencia de la incertidumbre laboral». En: PACHeco, Edith; Garza, Enrique de la y Reygadas, Luis (coords.). Trabajos atípicos y precarización en el empleo. México: El Colegio de México.

SALAs, Carlos (2007). «Empleo y trabajo en México 2001-2006: Un balance inicial». Trabajo, 3 (4), 137-161.

SANTAmaría, Elsa (2012). "Jóvenes y precariedad laboral: Trayectorias laborales por los márgenes del empleo». Zerbitzuan [en línea], 52, 129-139. <http://dx.doi.org/10.5569/1134-7147.52.08>.

Tashakkori, Abbas y Teddlie, Charles (1998). Mixed Methodology.Combining Qualitative and Quantiative Approaches. Thousand Oaks: Sage Publications

ToKman, Víctor (1979). «Dinámica del mercado de trabajo urbano: El sector informal urbano en América Latina». En: Katzman, Rubén y Reyna, José Luis (coords.). Fuerza de trabajo y movimientos laborales en América Latina. México, D. F.: El Colegio de México.

Torns, Teresa (2005). «De la imposible conciliación a los permanentes malos arreglos». Cuadernos de Relaciones Laborales, 23 (1), 15-33.

Villarreal, René (1988). «La reconversión en la siderurgia paraestatal de México». Comercio Exterior, 38 (3), 91-201.

WELLER, Jürgen (2014). "Aspects of recent developments in the Latin American and Caribbean labour markets». CEPAL Review, 114, 7-22.

Zapata, Francisco (1993). «La crisis del control sindical sobre la dinámica del trabajo en México». En: Reestructuración y regulación institucional del mercado de trabajo en América Latina. Ginebra: International Institute of Labor Studies. Serie de Investigación 98. 